\title{
Spectroscopic Analysis of Impurity Precipitates in CdS Films
}

J.D. Webb, J. Keane, R. Ribelin, L. Gedvilas, A. Swartzlander, K. Ramanathan, D.S. Albin, And R. Noufi

National Renewable Energy Laboratory

Presented at the National Center for

Photovoltaics Program Review Meeting

Denver, Colorado

September 8-11, 1998

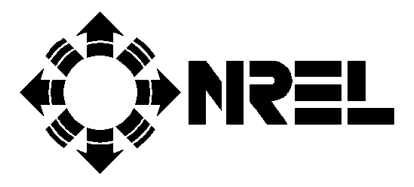

National Renewable Energy Laboratory 1617 Cole Boulevard Golden, Colorado 80401-3393

A national laboratory of the U.S. Department of Energy Managed by Midwest Research Institute for the U.S. Department of Energy under contract No. DE-AC36-83CH10093

Work performed under task number PV903101

October 1998 


\begin{abstract}
NOTICE
This report was prepared as an account of work sponsored by an agency of the United States government. Neither the United States government nor any agency thereof, nor any of their employees, makes any warranty, express or implied, or assumes any legal liability or responsibility for the accuracy, completeness, or usefulness of any information, apparatus, product, or process disclosed, or represents that its use would not infringe privately owned rights. Reference herein to any specific commercial product, process, or service by trade name, trademark, manufacturer, or otherwise does not necessarily constitute or imply its endorsement, recommendation, or favoring by the United States government or any agency thereof. The views and opinions of authors expressed herein do not necessarily state or reflect those of the United States government or any agency thereof.
\end{abstract}

Available to DOE and DOE contractors from:

Office of Scientific and Technical Information (OSTI)

P.O. Box 62

Oak Ridge, TN 37831

Prices available by calling 423-576-8401

Available to the public from:

National Technical Information Service (NTIS)

U.S. Department of Commerce

5285 Port Royal Road

Springfield, VA 22161

703-605-6000 or 800-553-6847

or

DOE Information Bridge

http://www.doe.gov/bridge/home.html 


\title{
Spectroscopic Analysis of Impurity Precipitates in CdS Films
}

\author{
J. D. Webb, J. Keane, R. Ribelin, L. Gedvilas, A. Swartzlander, \\ K. Ramanathan, D. S. Albin, R. Noufi
}

National Renewable Energy Laboratory (NREL), Golden, CO 80401-3393

\begin{abstract}
Impurities in cadmium sulfide (CdS) films are a concern in the fabrication of copper (indium, gallium) diselenide (CIGS) and cadmium telluride (CdTe) photovoltaic devices. Devices incorporating chemical-bath-deposited (CBD) $\mathrm{CdS}$ are comparable in quality to devices incorporating purer $\mathrm{CdS}$ films grown using vacuum deposition techniques, despite the higher impurity concentrations typically observed in the CBD CdS films. In this paper, we summarize and review the results of Fourier transform infrared (FTIR), Auger, electron microprobe, and Xray photoelectron spectroscopic (XPS) analyses of the impurities in CBD CdS films. We show that these impurities differ as a function of substrate type and film deposition conditions. We also show that some of these impurities exist as $10^{2}$ micron-scale precipitates.
\end{abstract}

\section{INTRODUCTION}

Cadmium sulfide (CdS) plays an essential role in the creation of junctions, buffers, or passivation layers in thin-film photovoltaic (PV) devices (1). The best device performance has historically been achieved with solar cells incorporating CdS films grown by $\mathrm{CBD}$, rather than $\mathrm{CdS}$ films grown using other methods, such as physical vapor deposition (PVD) (2), although CdTe devices with near-record efficiencies have recently been grown on close-spaced sublimated CdS films (3). Recently, considerable attention has been focused on the effects of components of the CBD solution on CIGS PV films (4) and on side products of the CBD reaction. Typical CBD solutions contain a soluble cadmium salt, ammonia, and thiourea (4), and sometimes use triethanolamine as a complexing agent for cadmium ion (1) or an ammonium salt as a $\mathrm{pH}$ buffer (2). Cadmium cyanamide $(\mathrm{CdNCN})$ and $\mathrm{Cd}(\mathrm{OH})_{2}$ have been identified $(1,5)$ in $\mathrm{CBD} \mathrm{CdS}$ films. Urea (1) and cyanamide $(\mathrm{HNCNH}, 5)$ have been identified as the primary products of the CBD reaction. Hydroxyl ions $\left(\mathrm{OH}^{-}\right)$, water $\left(\mathrm{H}_{2} \mathrm{O}\right)$, cyanamides, and carbonates were detected in CBD CdS films, but not in evaporated CdS films $(6,7)$.

The variety of possible products and by-products of the CBD reaction, and the potential for aqueous ammonia to act as a complexing agent for both cadmium $(1,8)$ and copper (8) ions, suggest that minor variations in the CBD process chemistry may have a significant influence on the CdS/CIGS interface and on the performance of the resulting devices (8). In CdTe thin-film PV devices, which are grown on CdS substrates to form an active heterojunction, the $\mathrm{CBD}$ process for $\mathrm{CdS}$ has produced high efficiencies (9), although alternatives to the CBD process, such as close-spaced sublimation, are being actively pursued $(9,10)$ and have excelled in some cases $(3)$. 


\section{EXPERIMENTAL APPROACH}

FTIR micro-spectroscopy was used in this work in concert with micro- and macroscale surface analytical techniques (11). The samples analyzed nominally consisted of IR-transparent films on IR-reflective substrates $\left(\mathrm{Mo}\right.$ or $\left.\mathrm{SnO}_{2}\right)$; any film contaminants will absorb IR radiation at frequencies characteristic of the particular contaminant(s). The Nicolet NicPlan FTIR microscope can obtain infrared reflectance (R) spectra of sample areas as small as $20 \times 20 \mu \mathrm{m}$. The $\mathrm{R}$ spectra were converted to reflection-absorbance $(\mathrm{RA}=-\log [1 / \mathrm{R}])$ spectra to facilitate comparison with infrared spectral databases (which are stored in absorbance units) for pure chemical compounds. The FTIR microscope can be set to automatically scan a preset traverse or grid of the sample, record the spectra at each traverse or grid point, and prepare a two- or threedimensional Amap@of the intensity of infrared absorbance associated with a given chemical species versus sample position. FTIR specular reflectance (SR) spectroscopy enables RA analysis of a $1-\mathrm{cm}^{2}$ area of the samples for overall contaminant detection. An electron probe microanalysis (EPMA) system operated at $10 \mathrm{kV}$, a scanning Auger nanoprobe, and an XPS system were also used in this work (11).

\section{RESULTS AND DISCUSSION}

In (11), we used scanning FTIR micro-spectroscopy and EPMA to identify absorbed water and copper carbonates in one of numerous $1 \mathrm{~B} 50-\mu \mathrm{m}$ orange inclusions visible in an experimental CBD CdS/CIGS/Mo PV device without a $\mathrm{ZnO}$ overlayer. Figure 1 shows a map of carbonate absorbance (shaded peak) vs. position. Our EPMA analyses show that the spot protrudes many times the EPMA sampling depth $(\sim 1 \mu \mathrm{m}$ for CdS $)$ above the CdS film surface, that it contains carbon, oxygen, copper, indium, and selenium in addition to cadmium and sulfur, but does not contain nitrogen or gallium. EPMA analyses of areas near the spot show only CdS.

Our interpretation of these results is that the spot contains normal or basic copper carbonate (12), which could have resulted from a side reaction between the CIGS film (or its surface oxides and selenides, 13) and the CBD bath. The CBD process for this sample involved the reaction of thiourea with cadmium acetate in ammonia-buffered aqueous solution at $75^{\circ} \mathrm{C}$. Copper oxides and selenides are soluble in aqueous ammonia (12). Carbonates and bicarbonates can precipitate from solutions containing $\mathrm{CO}_{2}$ and metal ions, and $\mathrm{CO}_{2}$ is readily evolved from heated basic solutions of acetates (14), such as the ammoniated CBD bath. An alternative route for carbonate ion formation has been postulated as a result of absorption of atmospheric $\mathrm{CO}_{2}$ by the basic CBD solution (6). Carbonates have been observed on the surfaces of similar devices by using large-area FTIR and XPS analyses (6). Our work indicates that the carbonates are in the form of localized precipitates on the device surfaces. We note that the CBD solution will preferentially dissolve copper from stoichiometric CIS (15); similar dissolution of copper from CIGS could result in precipitation of copper-containing impurities onto CIGS films in some CBD recipes.

To further investigate the CBD reaction chemistry, we prepared a series of 50-nmthick $\mathrm{CdS}$ films on Mo/glass substrates using our standard CBD process for CIGS substrates, with $\mathrm{CdSO}_{4}$ as the cadmium source, $40^{\circ} \mathrm{B} 70^{\circ} \mathrm{C}$ deposition temperature, and 100:1 molar ratio of thiourea to $\mathrm{Cd}(15)$. The glass substrates were either cerium oxidepolished soda-lime glass or Corning 7059 sodium-free glass. We analyzed these 

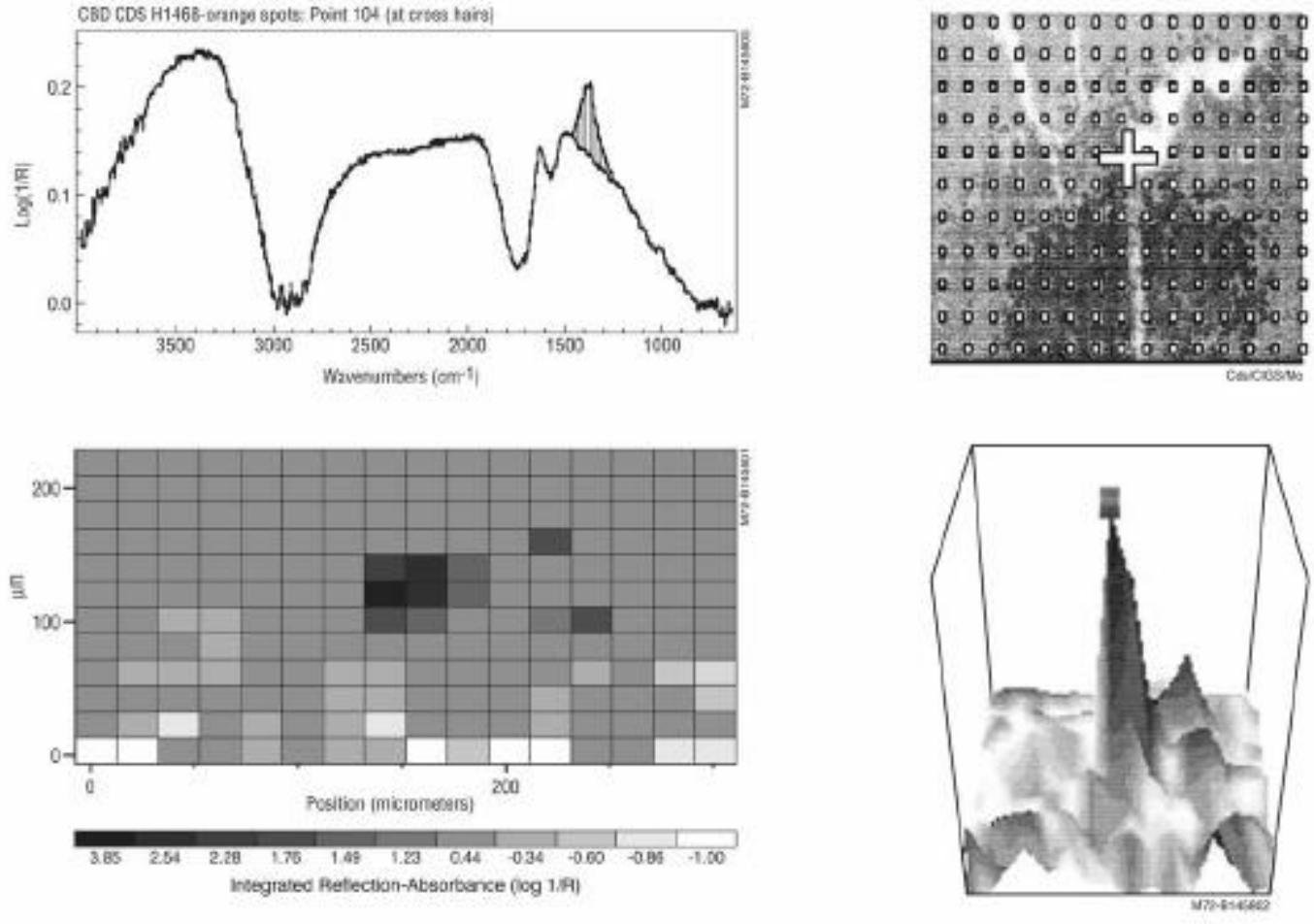

Fig. 1. FTIR microspectroscopic analysis of 50- $\mu \mathrm{m}$ orange spot on $\mathrm{CdS} / \mathrm{CIGS} / \mathrm{Mo}$ sample.

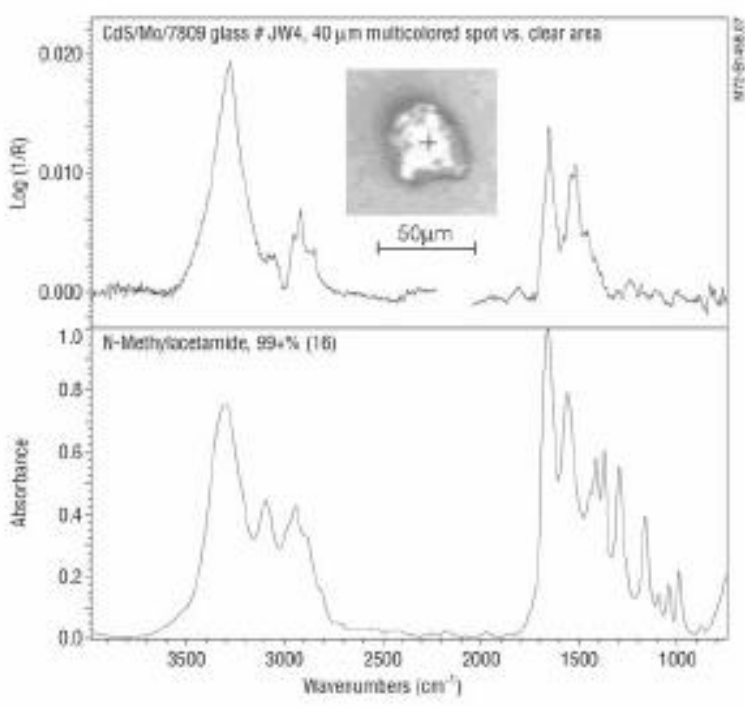

Fig. 2. Micro-FTIR-RA spectrum of $40 \mu \mathrm{m}$ spot on CdS/Mo/ 7059 glass, compared to spectra of possible constituents.

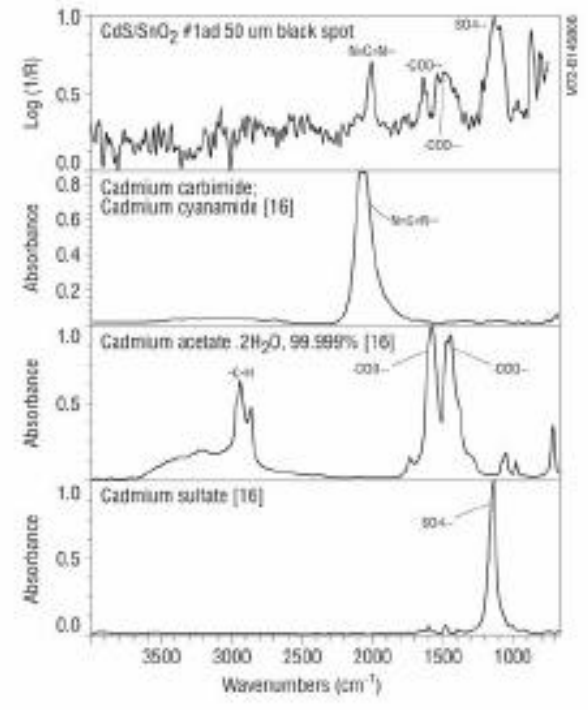

Fig. 3. FTIR microreflectance spectrum of 50- $\mu \mathrm{m}$ black spot on as-deposited $\mathrm{CdS} / \mathrm{SnO}_{2}$ sample, with library spectra [16] of probable contaminants. 
samples using FTIR SR and micro-reflectance spectroscopy in conjunction with spectral database searches (16). The large-area SR spectra of the samples versus a goldcoated silicon wafer exhibited no contaminant absorbance peaks. However, when viewed through the visible-light optics of the FTIR microscope, the samples exhibited a number of precipitates large enough for FTIR microanalysis, i.e., with diameters $>20$ $\mu \mathrm{m}$. Precipitate coverage of about one large particle $/ \mathrm{cm}^{2}$ was observed, and many more particles too small to analyze were visible on the samples. Database searching (16) of the FTIR spectra of the particles found matches to acetamide (Figure 2) or urea compounds for both substrate types. In addition to these particulate types, sulfate or molybdate-containing particles were identified in the CdS films on Mo/soda-lime glass, while hydrocarbons and silicates were found in particles in the CdS films on Mo/7059 glass. Precise matches to carbonates were not found in the CdS/Mo samples, in contrast to the CdS/CIGS/Mo sample (Figure 1). It is possible that carbonate formation is favored when a CIGS film, which makes soluble metallic counter-ions available during $\mathrm{CBD}$, is present. We have found good matches to carbonate and bicarbonate species in the FTIR micro-reflectance spectra of large $(100 \mathrm{~B} 400 \mu \mathrm{m})$, sodium-containing dark spots on the surfaces of CIS/Mo films prepared both with and without added sodium $(17,18)$. This indicates that carbonates could even be present before CBD on some CIGS films, as a product of the reaction of sodium with atmospheric oxygen and carbon dioxide. Work in this area is continuing, with spectroscopic microanalyses of additional CIGS/Mo and CdS/CIGS/Mo samples currently in progress.

We also examined a series of CBD CdS films, 0.07B0.10- $\mu \mathrm{m}$ thick, on Corning 7059 glass substrates coated with $\mathrm{SnO}_{2}: \mathrm{F} / \mathrm{iSnO}_{2}(19)$. These samples are typical substrates for $\mathrm{CdTe}$ deposition, and contained numerous visible anomalies in the form of spots $50 \mathrm{~B} 100 \mu \mathrm{m}$ in diameter. The CBD process for these samples involved the reaction of a 2:1 molar ratio of thiourea and cadmium acetate in ammonia-ammonia acetate buffered aqueous solution at $86^{\circ} \mathrm{B} 90^{\circ} \mathrm{C}$, followed by ultrasonic agitation and rinsing in deionized (DI) water ("standard" $\mathrm{CdS} / \mathrm{SnO}_{2}$ procedure, see 20). Using FTIR microspectroscopy and searches of spectral databases (16), we have identified acetate, sulfate, and cyanamide ionic species in black spots visible on or in the as-deposited CBD CdS films (Figure 3). The cyanamide ionic species (probably cadmium cyanamide) can be distinguished from cyanamide, the expected reaction product, by its lower vibrational frequency (16). The FTIR analyses were confirmed using the scanning Auger nanoprobe and XPS. The failure to remove the soluble acetate and sulfate precipitates through DI water rinsing could be explained if these precipitates were encapsulated by a thin $\mathrm{CdS}$ overlayer. In (11) we described the effects of annealing and hydrochloric acid rinsing in removing the various precipitate types. FTIR analyses showed that among the various annealing and rinsing procedures, only acid rinsing plus annealing in oxygen at $600^{\circ} \mathrm{C}$ completely removed the organic precipitates. Auger analyses showed that the acid rinse plus $600^{\circ} \mathrm{C}$ oxygen anneal left tin-rich spots on the sample surfaces, which are apparently voids through the $\mathrm{CdS}$ films to the $\mathrm{SnO}_{2}$ substrates.

Some of these voids were probably created by oxidation of included organic precipitates, as well as by evaporation of $\mathrm{SnS}$ phases from the CdS films (19).

We performed a study of the effect of variations in the CBD recipe for the $\mathrm{CdS} / \mathrm{SnO}_{2}$ films on impurity type and prevalence using FTIR SR spectroscopy and FTIR microspectroscopy. The "standard" CBD recipe (19) was modified by varying the thiourea/Cd and $\mathrm{Cd} / \mathrm{ammonium}$ acetate molar ratios, by varying the bath agitation procedures, or by adding a rinse with $100 \%$ acetic acid following the CBD process. 
The SR RA spectra of the samples, computed versus an uncoated $\mathrm{SnO}_{2} /$ glass background sample, showed a peak at $2000 \mathrm{~cm}^{-1}$, similar to the cadmium cyanamide absorbance shown in Figure 3. The intensity of this peak, normalized for film thickness, was used to gauge the level of cyanamide contamination in the samples. Varying the thiourea/Cd molar ratio from $0.7 \mathrm{~B} 8.0$ had little effect on the cadmium cyanamide band intensity, but increasing the $\mathrm{Cd} / \mathrm{ammonium}$ acetate ratio to 0.15 from its standard value of 0.06 correlated to an increase in cadmium cyanamide band intensity. FTIR-RA measurements showed that attempting to remove the cadmium cyanamide by rinsing the samples in glacial (100\%) acetic acid per (1) were unsuccessful, perhaps because the precipitates are encapsulated within the CdS film. The acid-rinsed samples also exhibited an FTIR-RA band at $757 \mathrm{~cm}^{-1}$, which is similar to the $816 \mathrm{~cm}^{-1}$ absorbance band that we measured using FTIR transmission micro-spectroscopy for stannous oxide ( $\mathrm{SnO}$, Aldrich Chemical Co.) particles dispersed in a potassium bromide pellet. Our measurement of the $816 \mathrm{~cm}^{-1} \mathrm{SnO}$ absorbance band is confirmed in the literature (21). The $757-\mathrm{cm}^{-1}$ band observed in the acid-rinsed samples is nearly identical in frequency to the $761-\mathrm{cm}^{-1}$ absorbance band characteristic of the stannous oxide trimer, $\mathrm{Sn}_{3} \mathrm{O}_{3}(21)$. The presence of stannous oxide in $\mathrm{CdS} / \mathrm{SnO}_{2}$ films has been postulated (19); encapsulation by $\mathrm{CdS}$ and the presence of reducing impurities in the CdS films may inhibit the expected oxidation of $\mathrm{SnO}$ to $\mathrm{SnO}_{2}$ in air. The $\mathrm{SnS}$ and $\mathrm{CdO}$ phases detected in the CdS films using x-ray techniques (19) cannot be confirmed using FTIR micro-spectroscopy because of the low frequency of their characteristic lattice absorbance bands (22).

A CdS sample grown using ultrasonic agitation plus magnetic stirring during the standard CBD process exhibited much higher cadmium cyanamide band intensity relative to the standard process, and also showed the stannous oxide peak. A sample grown using the standard procedure, with ultrasonic agitation but no stirring during $\mathrm{CBD}$, yielded a CdS film exhibiting low cyanamide band intensity and no stannous oxide RA peaks, similar to results obtained using the standard procedure. From the FTIR-SR results, we suspect that stirring deposits contaminants on the CdS films, which are then encapsulated during later stages of CBD. In comparison with the FTIRSR results from the CBD CdS/Mo samples, the standard process for the $\mathrm{CdS} / \mathrm{SnO}_{2}$ films yielded much higher contaminant levels. However, attempts to use the CBD process developed for $\mathrm{CdS} / \mathrm{CI}(\mathrm{G}) \mathrm{S}$ (15) initially did not yield uniform $\mathrm{CdS} / \mathrm{SnO}_{2}$ films, apparently because the $\mathrm{SnO}_{2}$ films have a much lower density of nucleation sites than CIGS films (23), although good quality $\mathrm{CdS} / \mathrm{SnO}_{2}$ films were obtained subsequently by slightly modifying this process (24). Our present "standard" CBD recipe for $\mathrm{CdS} / \mathrm{SnO}_{2}$ (20) was developed to overcome the uniformity problem (25).

Using the visible light optics of the FTIR microscope, we counted surface coverages of about 70B80 particles $/ \mathrm{cm}^{2}$ with diameter $>20 \mu \mathrm{m}$ on most of the $\mathrm{CdS} / \mathrm{SnO}_{2}$ samples-far higher than the precipitate coverage of about 1 particle $/ \mathrm{cm}^{2}$ observed on the CdS/Mo samples. In addition to the ionic cyanamide and stannate absorbances present in the FTIR-SR spectra, the micro-FTIR RA spectra of the CdS/SnO ${ }_{2}$ samples exhibited bands characteristic of ionic cyanates, sulfites, and sulfates, and also acetamides similar to the library spectrum bands shown in Figure 2. There was no clear correlation between the presence of these species and the variations in the CBD recipes described previously. 


\section{CONCLUSIONS}

The wide variety of chemical species observed in the $\mathrm{CdS}$ films is ascribed to variations in the CBD conditions and substrates. These species occur primarily as precipitates or precipitate clusters with diameters up to $200 \mu \mathrm{m}$. In the CdS/CIGS device, the dimensions and prevalence of the impurity-containing spots suggest that a fairly extensive reaction occurred between the CBD solution and the absorber film or its soluble contaminants to yield carbonates. In the $\mathrm{CdS} / \mathrm{SnO}_{2}$ samples, post-CBD annealing treatments alter the composition of the impurity precipitates, but do not remove them without leaving tin-rich spots behind. We infer from these results that modification of the $\mathrm{CBD}$ process to prevent codeposition of impurity precipitates in the $\mathrm{CdS}$ films, rather than post-CBD treatments, will prove most effective in producing clean, uniform $\mathrm{CdS}$ films. Although the CBD process for $\mathrm{CdS}$ yields high-quality devices in many cases (25), the size and extent of the precipitates observed suggest potential performance problems. The evidence for incorporated water and ionic salts in the precipitates, as well as their size, indicate that they could function as shunts or initiate delamination in a finished device. Although the low density of particulate contaminants found on the CdS/Mo samples is adequate for laboratory-scale devices, a particle density of $1 / \mathrm{cm}^{2}$ would be of concern during CIGS module manufacturing if the particles act as shunts or delamination centers. We have evidence that impurities in CBD CdS films facilitate delamination of CdTe from CdS (23). These observations provide impetus for developing alternatives to the CBD process for $\mathrm{CdS}$, while gaining an understanding of the positive effects of the CBD process on device performance. We expect that FTIR and surface spectroscopic techniques will continue to provide useful insights into these issues.

\section{ACKNOWLEDGMENTS}

The authors acknowledge the contributions of Alice Mason of NREL for providing EPMA analyses. We also thank Jeff Britt of Energy Photovoltaics (Lawrenceville, NJ 08648) and Andrew Gabor (Evergreen Solar, Waltham, MA 02154) for providing the CdS/CIGS sample, and Jennifer Granata of Colorado State University for providing the CIS/Mo samples. This work was performed under U.S. Department of Energy contract number DE-AC36-83CH10093.

\section{REFERENCES}

1. Sebastian, P.J., Campos, J., and Nair, P.K., Thin Solid Films 227, 190B195 (1993).

2. $\quad$ Li Sheng, S., Stanbery, B.J., Huang, C.H., Chang, C.H., Chang, Y.S., and Anderson,T.J., "Effects of Buffer Layer Processing on CIGS Excess Carrier Lifetime," 25th IEEE PVSC, 1996, pp. 821B824.

3. Ferekides, C., Marinskiy, D., and Morel, D. L., "'CdS: Characterization and recent advances in CdTe Solar Cell Performance," 26th IEEE PVSC, 1997, pp. 339-342.

4. Ramanathan, K., Contreras, M.A., Tuttle, J.R., Keane, J., Webb, J.D., Asher, S., Niles, D., Dhere, R., Tennant, A.L., Hasoon, F.L., and Noufi, R., "Effect of Heat Treatments and Window Layer Processing on the Characteristics of CuInGaSe 2 Thin Film Solar Cells," 25th IEEE PVSC, 1996, pp. 837B840.

5. Friedlmeier, T.M., Braunger, D., Hariskos, D., Kaiser, M., Wanka, H.N., and Schock, H.W., "Nucleation and Growth of the CdS Buffer Layer on $\mathrm{Cu}(\mathrm{In}, \mathrm{Ga}) \mathrm{Se}_{2}$ Thin Films," 25th IEEE PVSC, 1996, pp. 845B848.

6. Kylner, A., Rockett, A., and Stolt, L., "Oxygen in Solution-Grown CdS Films for Thin Film Solar Cells," Solid State Phenomena 51-52, 533B540 (1996). 
7. Niles, D.W., Herdt, G, and Al-Jassim, M., AAn X-Ray Photoelectron Spectroscopy Investigation of O Impurity Chemistry in CdS Thin Films Grown by Chemical Bath Deposition,@J. Appl. Phys. 81, 4, 1978B1994 (1997).

8. Webb, J.D., Keyes, B.M., Ramanathan, K., Dippo, P., Niles, D.W., and Noufi, R., AFT-PL Analysis of CIGS/CdS/ZnO Interfaces,@Proc. DOE/NREL Photovoltaic Program Review, Lakewood, CO, 1996, pp. 573B578.

9. Ferekides, C.S., Marinskiy, D., Marinskaya, B., Tetali, B., Oman, D., and Morel, D.L., ACdS Films Prepared by the Close-Spaced Sublimation and Their Influence on CdTe/CdS Solar Cell Performance,@ 25th IEEE PVSC, 1996, pp. 751B756.

10. Rose, D. H., Levi, D.H., Matson, R. J., Albin, D. S., Dhere, R.G., and Sheldon, P., AThe Role of Oxygen in CdS/CdTe Solar Cells Deposited by Close-Spaced Sublimation, @25th IEEE PVSC, 1996, pp. 777-780.

11. Webb, J. D., Rose, D.W., Swartzlander, A.W., and Al-Jassim, M.M., "FTIR, EPMA, Auger, and XPS analysis of Impurity Precipitates in CdS Films," 26th IEEE PVSC, 1997, pp. 399B402.

12. Lide, D.R. (ed.), CRC Handbook of Chemistry and Physics, 75th ed., Boca Raton, FL., CRC Press, pp. 4-56B4-58.

13. Tuttle, J.R.,Contreras, M., Tennant, A., Albin, D., and Noufi, R., "High-Efficiency Thin-Film Cu(In, $\mathrm{Ga}) \mathrm{Se}_{2}$-Based Photovoltaic Devices: Progress Towards a Universal Approach to Absorber Fabrication," 23rd IEEE PVSC, 1993, pp. 415B421.

14. Marsh, J., Advanced Organic Chemistry, 2nd ed., New York, McGraw-Hill, 1977, p. 569.

15. Ramanathan, K., Wiesner, H., Asher, S., Niles, D, Bhattacharya, R.N., Keane, J., Contreras, M.A., and Noufi, R., 2nd World Conference on Photovoltaic Solar Energy Conversion, Vienna, Austria, 1998 (in press).

16. Nicolet Instrument Corp., Madison, WI 53711., and Sadtler Div., Bio-Rad Laboratories, Philadelphia, PA 19104. The complete Nicolet digital library contains the mid-IR spectra of roughly 50,000 compounds (mostly organic chemicals). The Sadtler Select Inorganics digital library contains the mid-IR spectra of 1300 inorganic compounds. Both libraries include various correlation algorithms for comparing the spectra of unknown samples to the library spectra.

17. Granata, J.E., Sites, J.R., Asher, S., and Matson, R.J., "Quantitative Incorporation of Sodium in CuInSe ${ }_{2}$ and $\mathrm{Cu}(\mathrm{In}, \mathrm{Ga}) \mathrm{Se}_{2}$ Photovoltaic Devices," 26th IEEE PVSC, 1997, pp. 387-390.

18. Granata, J.E., and Sites, J.R., "Impact of Sodium in the Bulk and in Grain Boundaries of CuInSe ${ }_{2}, " 2 n d$ World Conference on Photovoltaic Solar Energy Conversion, Vienna, Austria, 1998 (in press).

19. Albin, D., Rose, D., Dhere, R., Niles, D., Swartzlander, A., Mason, A., Levi, D., Moutinho, H., and Sheldon, P., "Tin Oxide Stability Effects," Proc. DOE/NREL Photovoltaic Program Review, Lakewood, CO, 1996, pp. 665B681.

20. Rose, D.H., Albin, D.S., Matson, R.J., Swartzlander, A.B., Li, S., Dhere, R.G., Asher, S., Hasoon, F.S., and Sheldon, P., "Effects of Oxygen During Close-Spaced Sublimation of CdTe Solar Cells," Proc. MRS 426, 1996, pp. 337B348.

21. Ogden, J. S., and Ricks, M. J., "Matrix Isolation Studies of Group IV Oxides," J. Chem. Phys. 53, 3, 896903 (1997).

22. Popovic, Z. V., Stanisic, G., Stojanovic, D. and Kostic, R., "Infrared and Raman Spectra of CdO," Phys. Stat. Sol. (b) 165, 1991, pp. K109-K112. The FTIR transmission spectrum of a dispersion of SnS in a $\mathrm{KBr}$ pellet showed a peak at $610 \mathrm{~cm}^{-1}$, which is beyond the $7800-650 \mathrm{~cm}^{-1}$ frequency range of the FTIR microscope, but is within the range of large-area FTIR SR spectroscopy $\left(7800-400 \mathrm{~cm}^{-1}\right)$. The CdS absorbance band at $610 \mathrm{~cm}^{-1}$ is also difficult to distinguish from the broad absorbance band between 610 and $670 \mathrm{~cm}^{-1}$, which we measured for a dispersion of $\mathrm{SnO}_{2}$ in a $\mathrm{KBr}$ pellet.

23. Albin, D. S., unpublished work, August 1998.

24. Ramanathan, K., unpublished work, 1993. Attempts to create good CdTe devices on these $\mathrm{CdS} / \mathrm{SnO}_{2}$ substrates were unsuccessful, although the low efficiencies apparently resulted from the device fabrication procedures used at the time, rather than from the quality of the CdS films.

25. Zweibel, K., Ullal, H. S., and Von Roedern, B., "Progress and Issues in Thin-Film PV Technologies," 25th IEEE Photovoltaic Specialists Conference, 1996, pp. 745B750. 